OPEN ACCESS

Edited by:

Cordula Enenkel,

University of Toronto, Canada

Reviewed by:

Olivier Coux,

UMR5237 Centre de Recherche en

Biologie Cellulaire de Montpellier

(CRBM), France

Teru Ogura

Kumamoto University, Japan

*Correspondence:

Huib Ovaa

h.ovaa@/umc.n

tThese authors have contributed equally to this work and are Co-first

authors

Specialty section:

This article was submitted to Protein Folding, Misfolding and Degradation,

a section of the journal

Frontiers in Molecular Biosciences

Received: 14 January 2019 Accepted: 01 March 2019 Published: 22 March 2019

Citation:

Gan J, Leestemaker Y, Sapmaz A and Ovaa H (2019) Highlighting the Proteasome: Using Fluorescence to Visualize Proteasome Activity and Distribution. Front. Mol. Biosci. 6:14. doi: 10.3389/fmolb.2019.00014

\section{Highlighting the Proteasome: Using Fluorescence to Visualize Proteasome Activity and Distribution}

\author{
Jin Gan ${ }^{\dagger}$, Yves Leestemaker ${ }^{\dagger}$, Aysegul Sapmaz and Huib Ovaa* \\ Department of Cell and Chemical Biology, Oncode Institute, Leiden University Medical Centre, Leiden, Netherlands
}

Proteasomes are critical proteases in the cell responsible for the turnover of many cytoplasmic and nuclear proteins. They are essential for many cellular processes and various diseases are associated with their malfunctioning. Proteasome activity depends on the nature of the catalytic subunits, as well as the interaction with associated proteasome regulators. Here we describe various fluorescence-based methods to study proteasome function, highlighting the use of activity-based probes to study proteasome localization, dynamics, and activity in living cells.

Keywords: proteasome, fluorescence, activity, distribution, probe

\section{INTRODUCTION}

To maintain cellular homeostasis, cells must balance the synthesis and degradation of cellular constituents. Proteins can fail to fold correctly during protein synthesis or can become damaged under various stress conditions e.g., oxidative stress. When this occurs, aberrant proteins must be swiftly removed to protect the cell from undesired protein activity and the formation of potentially harmful protein aggregates (Glickman and Ciechanover, 2002). In addition, the selective and timely removal of intracellular signaling proteins by degradation is important for the regulation of protein signaling pathways. In mammalian cells, degradation of intracellular proteins is carried out by two major pathways. The first pathway is the ubiquitin-proteasome system (UPS) and it is responsible for $\sim 70 \%$ of all intracellular protein degradation in proliferating cultured cells (Rock et al., 1994). The second degradation pathway is autophagy which results in the lysosomal degradation of cellular components and organelles (Ebrahimi-Fakhari et al., 2011). The UPS unfolds and cleaves proteins into small polypeptide fragments with a typical length between 8 and 10 amino acids. These fragments can be broken down further by other proteases providing a source of amino acids for the synthesis of new peptides. In addition, these peptide fragments can be presented by the human major histocompatibility complex-1 (MHC-I), which is present on the cell surface of all nucleated cells, to cells of the immune system (Groettrup et al., 2010). Since protein degradation is essential for many cellular processes, disruption of normal proteasome function can contribute to disease (Glickman and Ciechanover, 2002). The proteasome has been implicated to play a role in neurodegenerative diseases, various cancers, immune-related diseases, and aging (Schmidt and Finley, 2014). Modulation of 26 S proteasome activity has a proven therapeutic potential (Eldridge and O'Brien, 2010). Since the regulation of $26 S$ proteasome activity is complex, there is a high demand for assay reagents that can report both proteasome activity as well as localization. This review provides a summary of the fluorescent tools that are currently available. Table 1 provides an overview of the reagents discussed below. 
TABLE 1 | An overview of reagents or techniques (typical examples) to study proteasome activity or localization.

\begin{tabular}{|c|c|c|c|c|c|}
\hline Classes & Examples & Activity & Localization & $\begin{array}{l}\text { Cell } \\
\text { permeability }\end{array}$ & References \\
\hline \multirow[t]{4}{*}{$\begin{array}{l}\text { Peptide-based model } \\
\text { substrates }\end{array}$} & $\begin{array}{l}\beta 1: \text { Z-LLE-AMC, Z-LLE-NA, Ac-nLPnLD-AMC, } \\
\text { AC-GPLD-AMC, Z- nLPnLD-aminoluciferin }\end{array}$ & Yes & No & No & $\begin{array}{l}\text { Kisselev and Goldberg, } \\
\text { 2005; Moravec et al., } 2009\end{array}$ \\
\hline & $\begin{array}{l}\text { B2: Bz-VGR-AMC, Boc-LRR-AMC, Z-ARR-AMC, } \\
\text { Bz-FVR-AMC, Boc-LSTR-AMC, Ac-RLR-AMC, } \\
\text { Z-LRR-aminoluciferin }\end{array}$ & Yes & No & No & \\
\hline & Nonapeptides: LFP, LF-2 & Yes & No & No & $\begin{array}{l}\text { Smith et al., 2005; Jastrab } \\
\text { et al., } 2015\end{array}$ \\
\hline & FRET reporter 1 & Yes & No & No & Coleman and Trader, 2018 \\
\hline \multirow[t]{3}{*}{$\begin{array}{l}\text { Protein-based model } \\
\text { substrates }\end{array}$} & $\begin{array}{l}U_{b_{4}}(\mathrm{~K} 48)-U b-G F P-T a i l, ~ U b_{8}(K 48)-U b-G F P-T a i l, \\
\mathrm{Ub}_{4}(\mathrm{~K} 63)-U b-G F P-T a i l, \mathrm{~b}_{4}(\mathrm{~K} 11)-U b-G F P-T a i l \\
\text { Tail-GFP-Ub-Ub }_{4}(\mathrm{~K} 63) \text {, } \\
\mathrm{Ub}_{2}(\mathrm{~K} 48)-U b_{2}(\mathrm{~K} 48) \text {-GFP-Tail }\end{array}$ & Yes & No & No & $\begin{array}{l}\text { Martinez-Fonts and } \\
\text { Matouschek, } 2016\end{array}$ \\
\hline & $\mathrm{Ub}_{4}$ (lin)-GFP-Tail & Yes & No & No & Singh Gautam et al., 2018 \\
\hline & UbLRad23_GFP-95 & Yes & No & No & Yu et al., 2016 \\
\hline \multirow[t]{4}{*}{$\begin{array}{l}\text { Fluorescently-tagged } \\
\text { proteins }\end{array}$} & ODC-GFP, Ub-R-GFP, Ub-L-GFP & Yes & No & $\mathrm{N} / \mathrm{A}$ & $\begin{array}{l}\text { Li et al., 1998; Dantuma } \\
\text { et al., } 2000\end{array}$ \\
\hline & YFP-PIk1 & Yes & No & $\mathrm{N} / \mathrm{A}$ & Lindon and Pines, 2004 \\
\hline & GFP- $\beta 1 i$ & No & Yes & $\mathrm{N} / \mathrm{A}$ & Reits et al., 1997 \\
\hline & DQ-ovalbumin & Yes & Yes & No & Rockel et al., 2005 \\
\hline Deg-On system & Deg-On, eDeg-On & Yes & No & $\mathrm{N} / \mathrm{A}$ & Zhao et al., 2014 \\
\hline \multirow[t]{2}{*}{ Subunit specific ABPs* } & $\beta 1 \mathrm{c} / \beta 1 \mathrm{i}$ - selective ABP & Yes & No & Yes & van Swieten et al., 2007 \\
\hline & $\begin{array}{l}\text { B1i/B1c: Cy5-NC001, BodipyFL-NC001, } \\
\text { BodipyFL-LU001c, Cy5-LU001i }\end{array}$ & Yes & No & No & de Bruin et al., 2016a,b \\
\hline
\end{tabular}

*There are comprehensive summaries about these probes available in other review articles (Carmony and Kim, 2013; Hewings et al., 2017).

\section{OVERVIEW OF HUMAN PROTEASOME}

The $26 \mathrm{~S}$ proteasome is a multi-subunit, ATP-dependent protease complex. It consists of a $20 \mathrm{~S}$ core particle (20S CP) capped on one or both sides by a $19 \mathrm{~S}$ regulatory particle (19S RP) (Groll et al., 2000). The 20S CP is composed of four stacked rings, each consisting of seven subunits. The outer two rings contain seven similar, yet distinct alpha subunits (named $\alpha 1-\alpha 7$ ). The inner two rings of the 20S CP consist of seven distinct beta subunits (named $\beta 1-\beta 7)$. Three of these beta subunits contain active sites with proteolytic activity. The constitutively expressed catalytically active subunits are $\beta 1, \beta 2$, and $\beta 5$, which display caspase-like, trypsin-like, and chymotrypsin-like activity, respectively. The $19 \mathrm{~S}$ $\mathrm{RP}$ is involved in the recognition, binding, deubiquitination, and unfolding of polyubiquitinated proteins. It is also involved in the translocation of the polypeptide chain into the interior of the 20S CP. Alternative regulatory particles have been reported, including the PA28 $\alpha \beta$ and PA28 $\gamma$ protein complexes, the PA200 proteasome-activating protein, and PI31 (Li et al., 2014).

In addition to the different regulatory particles, different isoforms of the 20S CP have also been described. In lymphoid tissues, or after stimulation with interferon $\gamma($ IFN- $\gamma$ ) in nonlymphoid tissues, the constitutive $\beta$ subunits can be replaced by the immunoproteasome subunits $\beta 1 \mathrm{i}, \beta 2 \mathrm{i}$, and $\beta 5 \mathrm{i}$ to form the immunoproteasome. Mixed-type proteasomes containing a combination of constitutive and immunoproteasomes have been described (Dahlmann et al., 2000). Also, proteasomes expressing tissue-specific subunits such as the thymoproteasome (containing $\beta 5$ t instead of $\beta 5$ ) (Murata et al., 2007) and the testisspecific proteasome (containing $\alpha 4 \mathrm{~s}$ instead of $\alpha 4$ ) have been observed (Uechi et al., 2014).

Proteasome activity is dynamically regulated depending on changing cellular needs. For instance, during fundamental cellular processes such as apoptosis, proliferation, or 
differentiation, the activity of the proteasome is altered (Schmidt and Finley, 2014). Environmental factors such as oxidative stress, disease states, or small molecules, can influence 26S proteasome activity as well (Aiken et al., 2011). One way in which proteasome activity is regulated is by posttranslational modifications. Proteasomal subunits, like many other proteins, can be modified by phosphorylation (VerPlank and Goldberg, 2017), N-acetylation, alkylation, O-glycosylation, S-glutathionylation, N-myristoylation, and oxidation of sulfurcontaining amino acid residues (Sorokin et al., 2009). These modifications affect both the activity as well as the localization of the $26 \mathrm{~S}$ complex. Proteasomes have also been shown to interact with a growing list of proteasome-interacting proteins (Hartmann-Petersen and Gordon, 2004), including chaperones, E3 ligases, and deubiquitinases which may lead to altered stability of the $26 \mathrm{~S}$ proteasome complex and/or its proteolytic activity (Tai et al., 2010).

Additionally, proteasome activity can be regulated by small molecule compounds (Huang and Chen, 2009). A wide variety of synthetic and natural inhibitors have been reported in the past 25 years. Proteasome inhibitors including bortezomib and carfilzomib have been used therapeutically for treatment of multiple myeloma and mantle cell lymphoma in patients (Kisselev et al., 2012; Teicher and Tomaszewski, 2015). In contrast, several drugs that increase $26 \mathrm{~S}$ proteasome activity have potential applications in the treatment of neurodegenerative diseases (Myeku and Duff, 2018).

\section{VISUALIZING PROTEASOME ACTIVITY}

\section{Peptide-Based Model Substrates}

The activity of both $20 \mathrm{~S}$ and $26 \mathrm{~S}$ proteasomes can be measured using small peptide-based substrates. This is the most classical way to study proteasome activity. These substrates are typically three to four amino acids in length and are attached to a fluorescent reporter molecule such as 7-amino-4-methylcoumarin(AMC) (Kisselev and Goldberg, 2005) or a bioluminescent reporter molecule such as aminoluciferin (Moravec et al., 2009). After cleavage of the substrate by the proteasome, the reporter molecule is no longer caged. For AMC-based substrates, the fluorescent signal can be detected directly, while aminoluciferin needs to be processed further by luciferase to generate signal. For each of the different catalytic activities of the proteasome, there are specific peptide substrates available (Table 1). This allows the different catalytic activities of the proteasome to be measured separately. Unfortunately, many fluorogenic substrates are not cell-permeable, and therefore only applicable for studying purified proteasomes, permeabilized cells, or cell lysates. Alternatively, the substrate Suc-LLVY-AMC had been microinjected into cell nuclei to investigate proteasome activity in living cells (Rockel et al., 2005). Also, most substrates are processed by both the constitutive and immunoproteasome catalytic subunits of the 20S CP. Some substrates can be non-specifically processed by other proteases besides the proteasome leading to high levels of background signal. Another shortcoming of these reagents is that they do not require poly-ubiquitination or processing by the regulatory particles, although the regulatory particles enhance the degradation rate of fluorogenic substrates by inducing 20S CP gate opening. Fluorogenic substrates also have an advantage of easily being applied for high-throughput screening (HTS). For example, Suc-LLVY-AMC was used as a probe to screen for small molecule agonists of purified 20S proteasome activity, and two compounds MK-866 and AM-404 were ultimately identified as bona fide stimulators (Trader et al., 2017). To improve the existing fluorescent peptide-based substrates, a peptide-based FRET reporter has been developed (Coleman and Trader, 2018). Compared to the classical peptide-based substrate described above, this reagent has a larger size resulting in slower degradation and increased dynamic range, and is also four times higher in sensitivity making it suitable for HTS. Nonapeptides are another type of fluorescence-based proteasome substrates. Just as the peptide-based FRET reporter, the larger molecule results in slower degradation by $20 \mathrm{~S}$ proteasome compared to shorter substrates. This feature makes them an ideal tool to study proteasome activators. For example, nonapeptide LFP is slowly degraded because its entry to $20 \mathrm{~S}$ proteasomes is prevented by the $\mathrm{N}$ termini of the $\alpha$ subunits, but PAN can stimulate LFP degradation as it triggers gate opening (Smith et al., 2005, 2007). Another nonapeptide, LF-2, was used in a study that identified a new proteasomal cofactor in Mycobacterium tuberculosis (Jastrab et al., 2015).

\section{Protein-Based Model Substrates}

Peptide-based model substrates differ from native polyubiquitinated proteasome substrates in that the latter requires recognition and processing by the proteasome regulatory particles before proteolysis. For studying the entire degradation process by the $26 \mathrm{~S}$ proteasome, poly-ubiquitinated model substrates would be valuable research tools. A dye-labeled polyubiquitinated substrate was described as an assay reagent for $26 \mathrm{~S}$ proteasome activity. The $\mathrm{N}$-terminus was enzymatically attached to a polyubiquitin chain to induce proteasome degradation, and the C-terminus was conjugated with Alexa Fluor 546 dye for fluorescence anisotropy measurements (Bhattacharyya et al., 2016). Moreover, several GFP-based substrates with polyubiquitin chains of defined lengths and specific linkages were developed for proteasome degradation assays (MartinezFonts and Matouschek, 2016). Recently, the same group described the development of a new model substrate consisting of linear tetraubiquitin fused to GFP expressing a degradation initiation region, which is highly suitable for HTS (Singh Gautam et al., 2018). However, producing these polyubiquitination chains is quite laborious, another type of substrate with ubiquitin-like (UbL) domains, rather than polyubiquitination chains are also available. UbL domains can also be recognized by the proteasome bypassing the need for ubiquitination. One example of such a substrate is UbL $\mathrm{Rad}^{\mathrm{a} 3}$-GFP-95 (Yu et al., 2016).

\section{Intracellular Model Substrates}

The poly-ubiquitinated model substrates reported so far are not cell-permeable. This is unfortunate, as it prevents us from studying the degradation of defined poly-ubiquitinated model 
substrates in a native environment. In mammalian cells it is possible to use overexpressed model substrates to determine $26 \mathrm{~S}$ proteasome activity. A common strategy is to fluorescently tag a substrate protein, and monitor its degradation, such as YFP-Plk1 (Lindon and Pines, 2004). Another example of such a model substrate is GFP fused to 37 amino acids of ornithine decarboxylase (ODC), a protein which is degraded in an ubiquitin-independent manner (Li et al., 1998; Pegg, 2006). Other examples of overexpressed GFP-based model substrates are fusion proteins that contain $\mathrm{N}$-end rule and ubiquitin fusion degradation (UFD) signals such as ubiquitin-R-GFP and ubiquitin-L-GFP (Dantuma et al., 2000). The Deg-on system is an expression-based system that translates the level of $26 \mathrm{~S}$ proteasome activity into a fluorescent output. In this system, the expression of GFP is repressed by a continuously expressed genetically encoded proteasome substrate. When proteasome activity is increased, the level of the proteasome substrate goes down, resulting in less GFP protein repression. This results in an increased level of GFP, which can be detected. Vice versa, when proteasome activity is decreased, the levels of the proteasome substrate will rise. This will increase GFP repression, leading to lower levels of GFP (Zhao et al., 2014).

\section{Activity-Based Proteasome Probes}

Activity-based proteasome probes (ABPs) are developed based on the covalent binding of small inhibitors with active site residues of catalytic subunits. A typical ABP consists of a warhead, a recognition element and a reporter tag (Figure 1A). The recognition element, either a small polypeptide, a small molecule, or a protein derivative, directs the probe to active enzyme for enhanced selectivity. Then the warhead with modest reactivity covalently reacts with the catalytic residues. The reporter tag can be an affinity tag such as biotin to allow for isolation or a fluorophore for fluorescence signal detection. The proteasome ABPs are generally classified as either subunit specific ABPs or broad spectrum ABPs based on their selectivity toward a specific or all of the catalytic subunits.

Broad spectrum ABPs are reactive to all proteasome catalytical subunits. These probes gain access to the binding target through the gated channel of the $20 \mathrm{~S}$ core particle rather than random diffusion. If the gate is closed, or the binding sites are occupied by a proteasome inhibitor (e.g., MG132), the fluorescence signal will decrease. Conversely, if the gate is open, more probe can enter into the 20S core particle, and the fluorescent signal will increase (Figure 1B). Dansyl-Ahx ${ }_{3}-\mathrm{L}_{3}-\mathrm{VS}$ was the first reported cellpermeable and directly detectable broad spectrum ABP (Berkers et al., 2005). It was subsequently optimized into two other classical proteasome probes BodipyTMR-Ahx $3-\mathrm{L}_{3}$-VS (MV151) (Verdoes et al., 2006) and $\mathrm{Me}_{4}$ Bodipy-Ahx $\mathrm{A}_{3}-\mathrm{L}_{3}$-VS (Berkers et al., 2007), by replacing the dansyl group with Bodipy fluorophores. This change made the probe more sensitive for fluorescence detection while keeping its activity-based and cell-permeable properties. This means that these probes can be used in cell lysates, living cells, as well as animal tissues (Figure 1D), and are suitable for a variety of monitoring techniques, including in-gel fluorescence scan, flow cytometry, and fluorescence microscopy
(Figure 1C). All these features make both of these probes widely used in proteasome-related studies nowadays.

The $\mathrm{Me}_{4}$ Bodipy- $\mathrm{Ahx}_{3}-\mathrm{L}_{3}$-VS probe was used in a flow cytometry-based HTS. Eleven small molecule compounds were identified as novel proteasome activators in living cells, and the p38 MAPK pathway was highlighted as a novel signaling pathway to modulate proteasome activity (Leestemaker et al., 2017). In another study, thermal proteome profiling revealed that CDK4/6 inhibitor palbociclib induces stabilization of the $20 \mathrm{~S}$ proteasome complex. When MCF7 cells were treated with palbociclib, the proteasome activity also increased as measured using Me4BodipyFL-Ahx $\mathrm{A}_{3}-\mathrm{L}_{3}$-VS probe (Miettinen et al., 2018). Furthermore, the MV151 can also label the $\beta 2$ and $\beta 5$ subunits of the Plasmodium proteasome and was applied in a flow cytometry-based screen to identify Plasmodium specific inhibitors that selectively kill parasites (Li et al., 2012). Beyond applications in cultured cells, both probes are broadly used in animal tissues, providing an easier way to study changes in proteasome activity and drug bioavailability when mice are administrated with proteasome inhibitors and activators (Verdoes et al., 2006; Berkers et al., 2007). In a recent study, isolated neural stem cells treated with $\mathrm{Me}_{4}$ BodipyFL-Ahx $3-\mathrm{L}_{3}$-VS probes revealed that quiescent neural stem cells (NSCs) have reduced proteasome activity compared to activated NSCs (Leeman et al., 2018). The MV151 probe has also been applied to plant science. When the Arabidopsis plants were sprayed with benzothiadiazole (BTH), the cytoplasmic proteasome activation could be monitored by MV151 using an in-gel fluorescence scanning approach (Gu et al., 2010).

Subunit-specific ABPs have a strong preference for a specific subunit type in an optimized range of probe concentration and reaction time. A comprehensive review article about these probes was recently published (Hewings et al., 2017). For example, a combination of subunit-specific ABPs with different fluorophores can enable visualization of all six catalytic subunits simultaneously by standard SDS-PAGE gel (de Bruin et al., $2016 b$ ). This combination was then used to identify new subunit selective compounds, such as $\beta 5$ c selective inhibitors (Xin et al., 2016). However, as these ABPs display poor cell permeability, efficient labeling requires the use of cell lysates. A cell-permeable $\beta 1 \mathrm{c} / \beta 1 \mathrm{i}$ - selective ABP is available, but the fluorescence labeling requires a two-step approach (van Swieten et al., 2007).

\section{VISUALIZING PROTEASOME DISTRIBUTION AND COMPOSITION}

\section{Proteasome Marker Antibodies}

The canonical approach to visualize proteasome distribution and composition is to use commercially available antibodies targeting various proteasome subunits in combination with microscopy. This approach is broadly applicable for all types of cells and with fixed tissues. However, this technique is quite invasive, as cell fixation, and permeabilization are necessary for antibody staining. Therefore, the accuracy of proteasome complex localization might be affected under the harsh treatment, like 
A

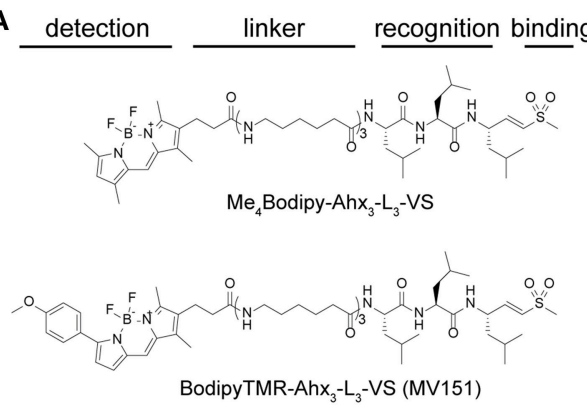

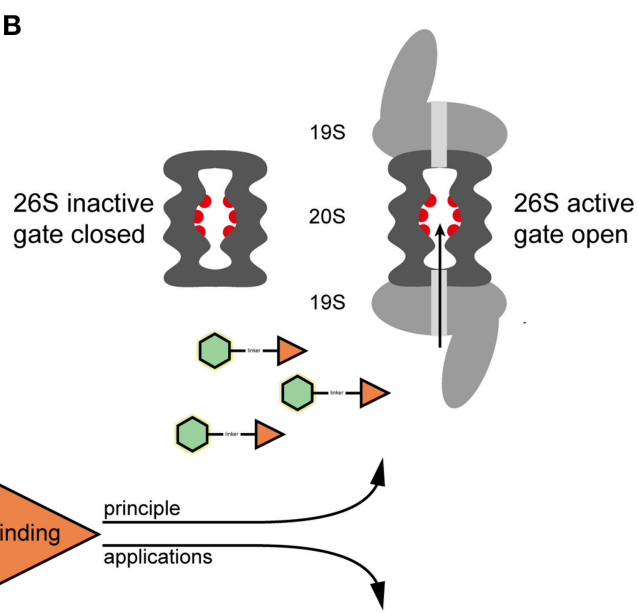

C

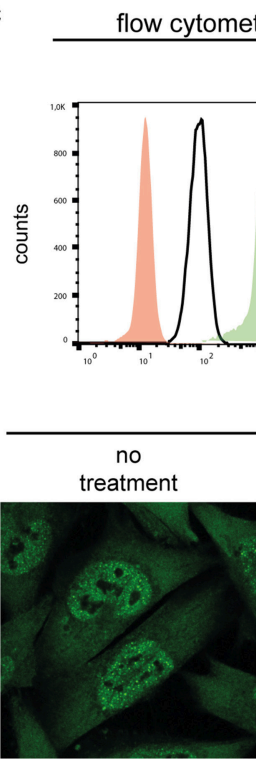

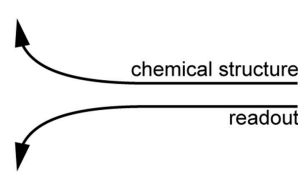

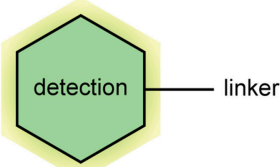

SDS-PAGE

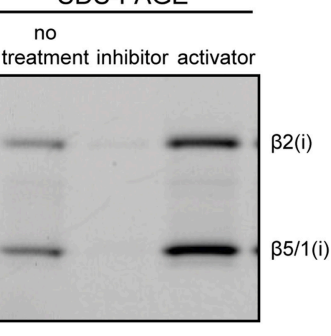

microscopy
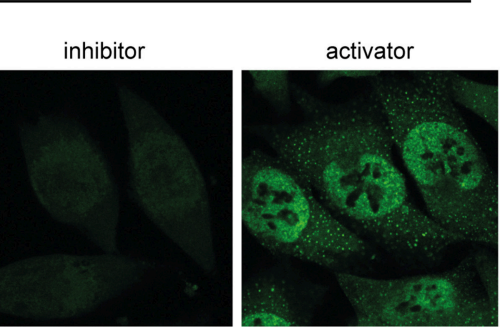

D

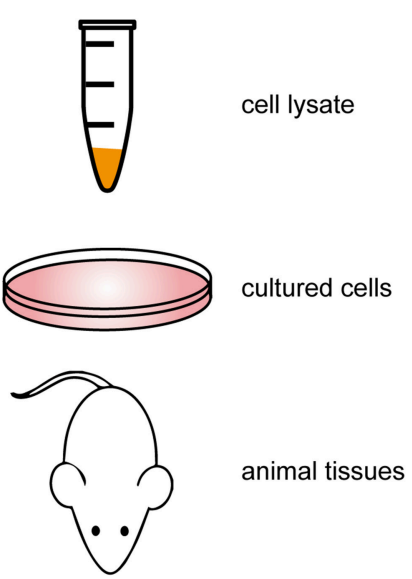

FIGURE 1 | Overview of proteasome ABPs. (A) Molecular structures of two proteasome ABPs. (B) The principle of how probes target the active proteasome: proteasome ABPs enter through the $20 \mathrm{~S}$ proteasome gate, and covalently target the catalytic sites. (C) Typical examples of the detection methods of proteasome ABPs. Left, overlay of the ABP signal in proteasome inhibitor treated (red), untreated (white), and proteasome activator treated (green) MelJuSo cells; Right, In-gel fluorescence scan showing representative proteasome activity profiles of proteasome inhibitor treated, untreated, and proteasome activator treated MelJuSo cells; Below, confocal microscopy images of the ABP signal in proteasome inhibitor treated, untreated and proteasome activator treated MelJuSo cells. (D) Applications of proteasome ABPs.

fixation with cold methanol. In addition, antibodies cannot differentiate between active and inactive proteasomes.

\section{Fluorescently-Tagged Approach}

Fluorescently-tagged proteasome subunits have been widely used to visualize proteasome distribution and dynamics in living cells for over two decades. GFP- $\beta 1 \mathrm{i}$ was the first subunit to be overexpressed and incorporated into the proteasome (Reits et al., 1997). Afterwards, several other subunits were also fluorescentlytagged and integrated into the proteasome (Salomons et al., 2010). The intracellular distribution of fluorescently-tagged proteasomes can be easily visualized in living cells under a fluorescence microscope (Enenkel, 2014). The dynamics of proteasomes can also be followed over time by photobleaching a small area in a living cell. Strategies include fluorescence recovery after photobleaching (FRAP) and fluorescence loss in photobleaching (FLIP) (Groothuis and Reits, 2005). Fluorescence correlation spectroscopy (FCS), was also used to study the concentration, dynamics, and complex formation of the $26 \mathrm{~S}$ proteasome in living yeast cells (Pack et al., 2014).

In addition, fluorescently tagged substrates can be used to study proteasome distribution. For example, the fluorogenic protein DQ-ovalbumin (DQ-Ova) was microinjected into the nuclei of cultured human cells to study the distribution of proteasome degradation in different nuclear compartments (Rockel et al., 2005). 
Furthermore, the co-localization or interaction between proteasome and substrate is observable by co-expressing differently tagged proteasome subunits and substrate proteins (Schipper-Krom et al., 2014). A shortcoming of this approach is that the fluorescence does not necessarily represent intracellular distribution of intact active proteasomes, because not all of the tagged subunits are efficiently incorporated in the proteasome complexes. The non-incorporated fractions can interfere with proteasome distribution. In addition, fluorescent pre-complexes without activity also exist in cells. Incorporation of subunits in proteasome complexes can be determined by several laborious ways: (1) proteasome complex immunoprecipitation with antibodies against different subunits; (2) sucrose density centrifugation or native gradient PAGE; (3) diffusion rate determination of the fluorescent subunits (Groothuis and Reits, 2005; Enenkel, 2012).

\section{ABP Based Approach}

Proteasome ABPs target the active proteasome specifically and show a similar proteasome distribution pattern when compared to fluorescently-tagged proteasomes in living cells. The dynamics of active proteasomes in living cells can be observed when cells are pretreated with proteasome inhibitors (Berkers et al., 2007). When mice are administered with MV151, proteasome activity profiles in different organs or tissues can also be visualized (Verdoes et al., 2006). Besides visualizing proteasome distribution, proteasome ABPs are valuable tools in studying proteasome composition, especially subunit-specific ABPs. Two different studies described the development of a set of FRET donors and acceptors that selectively target the proteasome catalytic subunits (Park et al., 2014; de Bruin et al., 2016a). Such reagents can be used to determine the different proteasome subtypes present in cells, i.e., distinguishing constitutive proteasomes from immunoproteasomes and mixed-type proteasomes. However, as these reagents are not cell-permeable, their application is limited to studying purified proteasomes, or cell lysates.

\section{CONCLUDING REMARKS}

Substrate-based fluorescent reporters are useful tools for visualizing proteasome activity but cannot be used to study

\section{REFERENCES}

Aiken, C. T., Kaake, R. M., Wang, X., and Huang, L. (2011). Oxidative stressmediated regulation of proteasome complexes. Mol. Cell Proteomics 10, R110 006924. doi: 10.1074/mcp.R110.006924

Berkers, C. R., van Leeuwen, F. W., Groothuis, T. A., Peperzak, V., van Tilburg, E. W., Borst, J., et al. (2007). Profiling proteasome activity in tissue with fluorescent probes. Mol. Pharm. 4, 739-748. doi: 10.1021/mp07 00256

Berkers, C. R., Verdoes, M., Lichtman, E., Fiebiger, E., Kessler, B. M., Anderson, K. C., et al. (2005). Activity probe for in vivo profiling of the specificity of proteasome inhibitor bortezomib. Nat. Methods 2, 357-362. doi: $10.1038 /$ nmeth759

Bhattacharyya, S., Renn, J. P., Yu, H., Marko, J. F., and Matouschek, A. (2016). An assay for $26 \mathrm{~S}$ proteasome activity based on fluorescence anisotropy the intracellular localization of active proteasomes. While use of antibodies and fluorescently-tagged proteasome subunits are ideal approaches to visualize proteasome distribution and dynamics, they do not demonstrate proteasome activity in cells. The newly developed ABPs are valuable bi-functional reagents to studying both proteasome activity and distribution.

Proteasome ABPs offer a series of valuable advantages over traditional assays due to some inherent features. First, ABPs display the availability and reactivity of the active proteasomes, rather than abundance, while antibody-based approaches detect the active and inactive forms of proteasome indiscriminately. Second, ABPs are applicable for use with cell lysates or living cells, instead of being limited to assays using purified proteasomes. Third, the proteasome activity can be monitored without prior knowledge of a natural or artificial substrate of the proteasome, which remains a bottleneck for many other assays. However, there are still some limitations for proteasome ABPs, the labeling is a covalent and irreversible reaction between the target and the probe. Therefore, labeled proteins are no longer active, and this may affect the subsequent cellular pathways in living cells. Despite this, proteasome ABPs can play more important roles in proteasome related studies.

\section{AUTHOR CONTRIBUTIONS}

JG, YL, and HO: conception and design; JG and YL: manuscript writing; JG, YL, AS, and HO: figure design and editing; HO: supervision. All authors approved the final version of the manuscript for publication.

\section{FUNDING}

$\mathrm{HO}$ is supported by a VICI grant from the Netherlands Organization for Scientific Research (NWO) (project 724.013.002).

\section{ACKNOWLEDGMENTS}

We thank Amy L. Palmer (Department of Biomedical Sciences, College of Veterinary Medicine, Oregon State University) for her critical reading and editing of the manuscript.

measurements of dye-labeled protein substrates. Anal. Biochem. 509, 50-59. doi: 10.1016/j.ab.2016.05.026

Carmony, K. C., and Kim, K. B. (2013). Activity-based imaging probes of the proteasome. Cell Biochem. Biophys. 67, 91-101. doi: 10.1007/s12013-013-9626-4

Coleman, R. A., and Trader, D. J. (2018). Development and application of a sensitive peptide reporter to discover 20 S proteasome stimulators. ACS Comb. Sci. 20, 269-276. doi: 10.1021/acscombsci.7b00193

Dahlmann, B., Ruppert, T., Kuehn, L., Merforth, S., and Kloetzel, P. M. (2000). Different proteasome subtypes in a single tissue exhibit different enzymatic properties. J. Mol. Biol. 303, 643-653. doi: 10.1006/jmbi.2000.4185

Dantuma, N. P., Lindsten, K., Glas, R., Jellne, M., and Masucci, M. G. (2000). Short-lived green fluorescent proteins for quantifying ubiquitin/proteasomedependent proteolysis in living cells. Nat. Biotechnol. 18, 538-543. doi: $10.1038 / 75406$ 
de Bruin, G., Xin, B. T., Florea, B. I., and Overkleeft, H. S. (2016a). Proteasome subunit selective activity-based probes report on proteasome core particle composition in a native polyacrylamide gel electrophoresis fluorescenceresonance energy transfer assay. J. Am. Chem. Soc. 138, 9874-9880. doi: 10.1021/jacs.6b04207

de Bruin, G., Xin, B. T., Kraus, M., van der Stelt, M., van der Marel, G. A., Kisselev, A. F., et al. (2016b). A set of activity-based probes to visualize human (Immuno)proteasome activities. Angew. Chem. Int. Ed. Engl. 55, 4199-4203. doi: 10.1002/anie.201509092

Ebrahimi-Fakhari, D., Cantuti-Castelvetri, I., Fan, Z., Rockenstein, E., Masliah, E., Hyman, B. T., et al. (2011). Distinct roles in vivo for the ubiquitin-proteasome system and the autophagy-lysosomal pathway in the degradation of $\alpha$-synuclein. J. Neurosci. 31, 14508-14520. doi: 10.1523/JNEUROSCI.1560-11.2011

Eldridge, A. G., and O'Brien, T. (2010). Therapeutic strategies within the ubiquitin proteasome system. Cell Death Differ. 17, 4-13. doi: 10.1038/cdd.2 009.82

Enenkel, C. (2012). Using native gel electrophoresis and phosphofluoroimaging to analyze GFP-tagged proteasomes. Methods Mol. Biol. 832, 339-348. doi: 10.1007/978-1-61779-474-2_23

Enenkel, C. (2014). Proteasome dynamics. Biochim. Biophys. Acta 1843, 39-46. doi: 10.1016/j.bbamcr.2013.03.023

Glickman, M. H., and Ciechanover, A. (2002). The ubiquitin-proteasome proteolytic pathway: destruction for the sake of construction. Physiol. Rev. 82, 373-428. doi: 10.1152/physrev.00027.2001

Groettrup, M., Kirk, C. J., and Basler, M. (2010). Proteasomes in immune cells: more than peptide producers? Nat. Rev. Immunol. 10, 73-78. doi: $10.1038 /$ nri2687

Groll, M., Bajorek, M., Kohler, A., Moroder, L., Rubin, D. M., Huber, R., et al. (2000). A gated channel into the proteasome core particle. Nat. Struct. Biol. 7, 1062-1067. doi: 10.1038/80992

Groothuis, T. A., and Reits, E. A. (2005). Monitoring the distribution and dynamics of proteasomes in living cells. Methods Enzymol. 399, 549-563. doi: 10.1016/S0076-6879(05)99037-X

Gu, C., Kolodziejek, I., Misas-Villamil, J., Shindo, T., Colby, T., Verdoes, M., et al. (2010). Proteasome activity profiling: a simple, robust and versatile method revealing subunit-selective inhibitors and cytoplasmic, defense-induced proteasome activities. Plant J. 62, 160-170. doi: 10.1111/j.1365-313X.2009.04122.x

Hartmann-Petersen, R., and Gordon, C. (2004). Proteins interacting with the 26S proteasome. Cell Mol. Life Sci. 61, 1589-1595. doi: 10.1007/s00018-004-4132-x

Hewings, D. S., Flygare, J. A., Wertz, I. E., and Bogyo, M. (2017). Activitybased probes for the multicatalytic proteasome. FEBS J. 284, 1540-1554. doi: $10.1111 /$ febs.14016

Huang, L., and Chen, C. H. (2009). Proteasome regulators: activators and inhibitors. Curr. Med. Chem. 16, 931-939. doi: 10.2174/0929867097875 81860

Jastrab, J. B., Wang, T., Murphy, J. P., Bai, L., Hu, K., Merkx, R., et al. (2015). An adenosine triphosphate-independent proteasome activator contributes to the virulence of Mycobacterium tuberculosis. Proc. Natl. Acad. Sci. U.S.A. 112, E1763-1772. doi: 10.1073/pnas.1423319112

Kisselev, A. F., and Goldberg, A. L. (2005). Monitoring activity and inhibition of 26S proteasomes with fluorogenic peptide substrates. Methods Enzymol. 398, 364-378. doi: 10.1016/S0076-6879(05)98030-0

Kisselev, A. F., van der Linden, W. A., and Overkleeft, H. S. (2012). Proteasome inhibitors: an expanding army attacking a unique target. Chem. Biol. 19, 99-115. doi: 10.1016/j.chembiol.2012.01.003

Leeman, D. S., Hebestreit, K., Ruetz, T., Webb, A. E., McKay, A., Pollina, E. A., et al. (2018). Lysosome activation clears aggregates and enhances quiescent neural stem cell activation during aging. Science 359, 1277-1283. doi: $10.1126 /$ science.aag3048

Leestemaker, Y., de Jong, A., Witting, K. F., Penning, R., Schuurman, K., Rodenko, B., et al. (2017). Proteasome activation by small molecules. Cell Chem. Biol. 24, 725-736 e727. doi: 10.1016/j.chembiol.2017.05.010

Li, H., Ponder, E. L., Verdoes, M., Asbjornsdottir, K. H., Deu, E., Edgington, L. E., et al. (2012). Validation of the proteasome as a therapeutic target in Plasmodium using an epoxyketone inhibitor with parasite-specific toxicity. Chem. Biol. 19, 1535-1545. doi: 10.1016/j.chembiol.2012.09.019
Li, X., Thompson, D., Kumar, B., and DeMartino, G. N. (2014). Molecular and cellular roles of PI31 (PSMF1) protein in regulation of proteasome function. $J$. Biol. Chem. 289, 17392-17405. doi: 10.1074/jbc.M114.561183

Li, X., Zhao, X., Fang, Y., Jiang, X., Duong, T., Fan, C., et al. (1998). Generation of destabilized green fluorescent protein as a transcription reporter. J. Biol. Chem. 273, 34970-34975. doi: 10.1074/jbc.273.52.34970

Lindon, C., and Pines, J. (2004). Ordered proteolysis in anaphase inactivates Plk1 to contribute to proper mitotic exit in human cells. J. Cell Biol. 164, 233-241. doi: $10.1083 /$ jcb. 200309035

Martinez-Fonts, K., and Matouschek, A. (2016). A rapid and versatile method for generating proteins with defined ubiquitin chains. Biochemistry 55, 1898-1908. doi: 10.1021 /acs.biochem.5b01310

Miettinen, T. P., Peltier, J., Härtlova, A., Gierlinski, M., Jansen, V. M., Trost, M., et al. (2018). Thermal proteome profiling of breast cancer cells reveals proteasomal activation by CDK4/6 inhibitor palbociclib. EMBO J. 37:e98359. doi: 10.15252/embj.201798359

Moravec, R. A., O’Brien, M. A., Daily, W. J., Scurria, M. A., Bernad, L., and Riss, T. L. (2009). Cell-based bioluminescent assays for all three proteasome activities in a homogeneous format. Anal. Biochem. 387, 294-302. doi: 10.1016/j.ab.2009.01.016

Murata, S., Sasaki, K., Kishimoto, T., Niwa, S., Hayashi, H., Takahama, Y., et al. (2007). Regulation of CD8+ T cell development by thymus-specific proteasomes. Science 316, 1349-1353. doi: 10.1126/science.1141915

Myeku, N., and Duff, K. E. (2018). Targeting the $26 \mathrm{~S}$ proteasome to protect against proteotoxic diseases. Trends Mol. Med. 24, 18-29. doi: 10.1016/j.molmed.2017.11.006

Pack, C. G., Yukii, H., Toh-e, A., Kudo, T., Tsuchiya, H., Kaiho, A., et al. (2014). Quantitative live-cell imaging reveals spatio-temporal dynamics and cytoplasmic assembly of the 26S proteasome. Nat. Commun. 5:3396. doi: $10.1038 /$ ncomms 4396

Park, J. E., Wu, Y., Carmony, K. C., Miller, Z., Sharma, L. K., Lee, D. M., et al. (2014). A FRET-based approach for identification of proteasome catalytic subunit composition. Mol. Biosyst. 10, 196-200. doi: 10.1039/C3MB70471H

Pegg, A. E. (2006). Regulation of ornithine decarboxylase. J. Biol. Chem. 281, 14529-14532. doi: 10.1074/jbc.R500031200

Reits, E. A., Benham, A. M., Plougastel, B., Neefjes, J., and Trowsdale, J. (1997). Dynamics of proteasome distribution in living cells. EMBO J. 16, 6087-6094. doi: 10.1093/emboj/16.20.6087

Rock, K. L., Gramm, C., Rothstein, L., Clark, K., Stein, R., Dick, L., et al. (1994). Inhibitors of the proteasome block the degradation of most cell proteins and the generation of peptides presented on MHC class I molecules. Cell 78, 761-771. doi: 10.1016/S0092-8674(94)90462-6

Rockel, T. D., Stuhlmann, D., and von Mikecz, A. (2005). Proteasomes degrade proteins in focal subdomains of the human cell nucleus. J. Cell Sci. 118, 5231-5242. doi: 10.1242 /jcs.02642

Salomons, F. A., Acs, K., and Dantuma, N. P. (2010). Illuminating the ubiquitin/proteasome system. Exp. Cell Res. 316, 1289-1295. doi: 10.1016/j.yexcr.2010.02.003

Schipper-Krom, S., Juenemann, K., Jansen, A. H., Wiemhoefer, A., van den Nieuwendijk, R., Smith, D. L., et al. (2014). Dynamic recruitment of active proteasomes into polyglutamine initiated inclusion bodies. FEBS Lett. 588, 151-159. doi: 10.1016/j.febslet.2013.11.023

Schmidt, M., and Finley, D. (2014). Regulation of proteasome activity in health and disease. Biochim. Biophys. Acta 1843, 13-25. doi: 10.1016/j.bbamcr.2013.08.012

Singh Gautam, A. K., Martinez-Fonts, K., and Matouschek, A. (2018). Scalable in vitro proteasome activity assay. Methods Mol. Biol. 1844, 321-341. doi: 10.1007/978-1-4939-8706-1_21

Smith, D. M., Chang, S. C., Park, S., Finley, D., Cheng, Y., and Goldberg, A. L. (2007). Docking of the proteasomal ATPases' carboxyl termini in the $20 \mathrm{~S}$ proteasome's alpha ring opens the gate for substrate entry. Mol. Cell 27, 731-744. doi: 10.1016/j.molcel.2007.06.033

Smith, D. M., Kafri, G., Cheng, Y., Ng, D., Walz, T., and Goldberg, A. L. (2005). ATP binding to PAN or the 26S ATPases causes association with the $20 \mathrm{~S}$ proteasome, gate opening, and translocation of unfolded proteins. Mol. Cell 20, 687-698. doi: 10.1016/j.molcel.2005.10.019

Sorokin, A. V., Kim, E. R., and Ovchinnikov, L. P. (2009). Proteasome system of protein degradation and processing. Biochemistry 74, 1411-1442. doi: $10.1134 / \$ 000629790913001 \mathrm{X}$ 
Tai, H. C., Besche, H., Goldberg, A. L., and Schuman, E. M. (2010). Characterization of the brain $26 \mathrm{~S}$ proteasome and its interacting proteins. Front. Mol. Neurosci. 3:12. doi: 10.3389/fnmol.2010.00012

Teicher, B. A., and Tomaszewski, J. E. (2015). Proteasome inhibitors. Biochem. Pharmacol. 96, 1-9. doi: 10.1016/j.bcp.2015.04.008

Trader, D. J., Simanski, S., Dickson, P., and Kodadek, T. (2017). Establishment of a suite of assays that support the discovery of proteasome stimulators. Biochim. Biophys. Acta Gen. Subj. 1861, 892-899. doi: 10.1016/j.bbagen.2017. 01.003

Uechi, H., Hamazaki, J., and Murata, S. (2014). Characterization of the testisspecific proteasome subunit alpha4s in mammals. J. Biol. Chem. 289, 12365-12374. doi: 10.1074/jbc.M114.558866

van Swieten, P. F., Samuel, E., Hernandez, R. O., van den Nieuwendijk, A. M., Leeuwenburgh, M. A., van der Marel, G. A., et al. (2007). A cell-permeable inhibitor and activity-based probe for the caspase-like activity of the proteasome. Bioorg. Med. Chem. Lett. 17, 3402-3405. doi: 10.1016/j.bmcl.2007.03.092

Verdoes, M., Florea, B. I., Menendez-Benito, V., Maynard, C. J., Witte, M. D., van der Linden, W. A., et al. (2006). A fluorescent broad-spectrum proteasome inhibitor for labeling proteasomes in vitro and in vivo. Chem. Biol. 13, 1217-1226. doi: 10.1016/j.chembiol.2006.09.013

VerPlank, J. J. S., and Goldberg, A. L. (2017). Regulating protein breakdown through proteasome phosphorylation. Biochem. J. 474, 3355-3371. doi: 10.1042/BCJ20160809
Xin, B. T., de Bruin, G., Huber, E. M., Besse, A., Florea, B. I., Filippov, D V., et al. (2016). Structure-based design of beta5c selective inhibitors of human constitutive proteasomes. J. Med. Chem. 59, 7177-7187. doi: 10.1021/acs.jmedchem.6b00705

Yu, H., Kago, G., Yellman, C. M., and Matouschek, A. (2016). Ubiquitin-like domains can target to the proteasome but proteolysis requires a disordered region. EMBO J. 35, 1522-1536. doi: 10.15252/embj.201593147

Zhao, W., Bonem, M., McWhite, C., Silberg, J. J., and Segatori, L. (2014). Sensitive detection of proteasomal activation using the Deg-On mammalian synthetic gene circuit. Nat. Commun. 5:3612. doi: 10.1038/ncomms4612

Conflict of Interest Statement: HO is a founder and shareholder of Ubiq Bio B.V.

The remaining authors declare that the research was conducted in the absence of any commercial or financial relationships that could be construed as a potential conflict of interest.

Copyright (C) 2019 Gan, Leestemaker, Sapmaz and Ovaa. This is an open-access article distributed under the terms of the Creative Commons Attribution License (CC $B Y)$. The use, distribution or reproduction in other forums is permitted, provided the original author(s) and the copyright owner(s) are credited and that the original publication in this journal is cited, in accordance with accepted academic practice. No use, distribution or reproduction is permitted which does not comply with these terms. 